ORIGINAL ARTICLE

\title{
A description of lip print pattern and lip shapes in children's and their parents among Abbottabad population in KPK, Pakistan.
}

\author{
Aftab Alam Tanoli ${ }^{1}$, Omair Khan Jadoon ${ }^{2}$, Nayella Nijat Bangash ${ }^{3}$, Qurrat UI Ain ${ }^{4}$
}

Article Citation: Tanoli AA, Jadoon OK, Bangash NN, Qurrat UI Ain. A description of lip print pattern and lip shapes in children's and their parents among Abbottabad population in KPK, Pakistan. Professional Med J 2022; 29(3):401-406.

https://doi.org/10.29309/TPMJ/2022.29.03.6648

ABSTRACT... Objective: To assess for any peculiar lip prints in relation to the lip shapes of individual, and determine the most common lip print type among the members of biological families. Study Design: Descriptive study. Setting: Department of Forensic Medicine \& Toxicology, Women Medical \& Dental College, Abbottabad. Period: January 2018 to June 2018. Material \& Methods: A total of 216 individuals (father, mother, both children's), who underwent descriptive study of lip impression collection without any anesthesia or drug, were enrolled into the present study. Father, mother and two babies of each family were selected. Lip prints of Father, mother and both babies of each family were recorded. Each lip of 54 offspring's was compared with the corresponding lip of his/her father mother and other baby. The segments of each lip of the offspring's that matched/ resembled with either of father mother and biological babies were recorded. Results: Out of 54-total families, biological babies of 19(35.18\%) families observed resemblance with father, whereas biological babies of $35(64.81 \%)$ families observed resemblance with mother. There was no definite identical lip print observed in any of the children. Furthermore, the prevalence of Type II lip prints was higher type present in males and in females. We observed that lip shape 7 was the most frequent lip shape type in most of individuals. Conclusion: Lip prints of study participants did not clearly match with each other, evenly distributed in both genders and distinctive similar to finger prints. The data did not show any specific association of the lip print type with lip shape. It is considered feasible to apply lip prints features in personal identification.

Key words: Biological Family, Cheiloscopy, Lip Prints, Personal Identification.

\section{INTRODUCTION}

Lip prints analysis is a less commonly applied procedure for Identification. although it is less time consuming, very simple to be perform, much less expensive ,easy to document and no need of sophisticated machines requirements, whereas currently used methods of individual identification predominantly focus on DNA analysis, dental record and finger prints which are complex to perform, very much expensive, need of sophisticated equipment's and machines required. ${ }^{1,2}$

From sixth week of intra uterine life we can Identify Lip patterns and the formation of upper lip will be almost completed by $9^{\text {th }}$ week intra uterine life. For the rest of human life they remain unchanged. ${ }^{3,4}$
If lip print patterns of an individual are collected, analysed and described by a detailed study work, this can lead to formulation of definite lip prints data bank., this anti-mortem record of data bank pattern can be very useful in identity purposes in sexual offences, in identification especially in cases of missing persons of biological family. This antimortem record of lip print pattern can be used to compare with postmortem records of deceased for personal identification. ${ }^{5}$

The identification of misplaced persons can be very helpful in the practice of misery resolve of friends and family. ${ }^{6}$ Individual Identification is a preliminary for death documentation and also for subjective, communal and legitimate motives. ${ }^{7}$
1. MBBS, M.Phil, Associate Professor Forensic Medicine, Women Medical College, Nawansher, Abbottabad, KPK. 2. MBBS, DMJ, Associate Professor Forensic Medicine, Ayub Medical College Abbottabad.

3. MBBS, DMJ, Senior Lecturer Forensic Medicine, Women Medical College Abbottabad.

4. MBBS, M.D, PGT Gynae \& Obstetrics Unit -2, Holy Family Hospital Rawalpindi.

\author{
Correspondence Address: \\ Dr. Aftab Alam Tanoli \\ Department of Forensic Medicine \\ Women Medical College, Nawansher, \\ Abbottabad, KPK. \\ drtanoli403@gmail.com
}

Article received on:

Accepted for publication:

$11 / 06 / 2021$

$25 / 08 / 2021$ 
If the suspected criminal individual has visited the crime scene, then the presence of lip prints are irrefutable fact if he/she has touched some frame glass, used cloths or crockery, consumed some food stuff or some drink. Presence of lip prints can provide a relationship between suspect and crime scene. A detained record of individual lips can be used to match with lip prints on crime scene for identification of culprits.

Keeping in view the importance of lip print patterns in personal identification, the present study was carried out to investigate and document the characteristic lip prints pattern and lip shapes which aids in individual discovery and to ascertain any heritable pattern in lip prints among families with siblings.

\section{MATERIAL \& METHODS}

This descriptive study was conducted from January 2018 to June 2018 at forensic medicine \& toxicology Department, women medical \& dental college, Abbottabad.

Nonprobability convenience sampling technique was used to collect sample. A total of 216 individuals, who underwent for collection of lips impression and lip shapes, were enrolled into the present study. The study was approved by the Ethical Committee of the women medical \& dental college Abbottabad (WMC/Estb/11239), and an informed consent was obtained from the mothers, father and 2 babies (either boys or girls) /guardians of children. A brief detail of our objectives were given to all participants and the questions relating to procedure were answered. In the present study, a total of 216 participants including mothers, father and 2 babies (either boys or girls) from each family were analyzed, which fulfilled the sample size requirements.

\section{Inclusion Criteria Were}

Those individuals who have normal lip skin and transition zone of mucosa and were included.

\section{Exclusion Criteria Were}

We excluded Individuals from our study if they have lips Inflammation, deformity, malformation, active lesions, surgical scars or impression material Hypersensitive. No drugs or chemical was used in study subjects.

Initially cleaning and drying of Individual's lips was done. On the lips of each individual a thin layer of lipstick was evenly applied in a single motion. After two minutes, the individuals were advised to maintain a relaxed lip position. Negligible pressure was sustained while making the lip impression and the glued portion of the cellophane tape fixed on to the white bond paper was used to make the lip impression. Lip prints on non-porous surfaces are better to be snapped and magnified so bond paper was preferred over tissue papers. This cellophane tape on bond paper served as a permanent record. Dark color (red / brown) nonmetallic, nonglossy lip stick give clear prints while the glossy or metallic lip stick bring seemingly good lip prints but their photographs were not clear for study. The impressions were afterward visualized with the magnifying lens.

54 families were collected and 4 members per family including father, mother and biological babies. We have divided in to 5 pairs in which we studied:

Verses $1^{\text {st }}$ baby Father (AC)

$2^{\text {nd }}$ baby verses Father (AD)

$1^{\text {st }}$ baby verses Mother ( $\left.B C\right)$

$2^{\text {nd }}$ baby verses Mother (BD)

$1^{\text {st }}$ baby verses $2^{\text {nd }}$ baby (CD)

The above mentioned data was recorded on predesigned performa and the lip print patterns were scrutinized in accordance of Suzuki and Tsuchihashi classification (Suzuki, K., Tsuchihashi, Y., 1970).

The data was entered and analyzed using SPSS 20.0 (Statistical Package for Social Sciences). Basic statistical techniques were used. Mean was calculated in all quadrants of individual lips. Frequency and percentages was calculated for resemblance among biological families and for gender. Z-test was applied to test the resemblance of lip prints to mother and father separately in the family. The data was represented in the form of tables and figures. 


\section{RESULTS}

The available data was used to generate the profile of resemblance of lip prints among members of biological family. The comparison was made between father lip prints and 02 biological babies, mother lip prints with 02 biological babies, first biological baby and both parents, second biological baby and both parents, and then amongst biological babies. The mean resemblance between father and 02 biological babies was found to be 58.335 while between mother and first baby was as 58.335 and between mother and second baby was as 70.835 . The mean resemblance between first baby and second baby was found to be 58.335 .

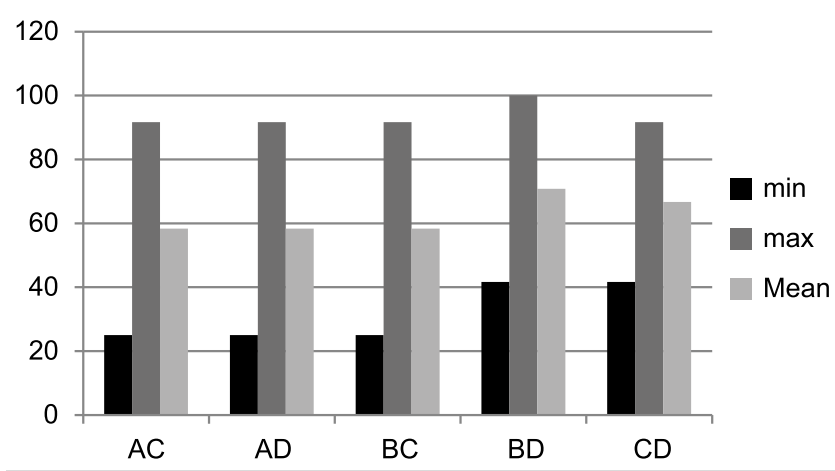

Figure-1. Mean, Min, Max resemblance of parents and babies.

In all of studied families, we calculated resemblance of father with his both babies and then we calculated resemblance of mother with both babies. Resemblance of fathers with his offsprings were found to be higher in 19(35.18\%) families, $\quad(z=0.4978, \quad p<0.05), \quad$ whereas resemblance of mothers with her off springs were found to be higher in in $35(64.81 \%)$ families. $(z=0.49917, p<0.05)$. Lip prints showed a strong positive and statistically significant correlation between parents and their biological babies.

We observed that mother resemblance towards babies was at higher level as compared with father resemblance. Father to mother resemblance ratio is $1: 1.8$.

Out of 54-twin families, 26 (51.85\%) were male babies pairs while 28 (48.14\%) were female babies pairs. Male to Female babies' pair ratio was 1: 1.2 .
Lip print types of all members of 54 families were studied. Lip print Type I, II, III and IV were found in both genders (males and females). Type II Lip print was most common type present in males and in females 913(70.8\%) \& 957(72.3\%) respectively. Type IV Lip print was second most common type in both males and in females $296(22.9 \%) 271(20.4 \%)$ respectively, followed by type II in males $49(3.8 \%)$ and in females $67(5.0 \%)$ and type III in males $30(2.3 \%)$ and in females $22(1.6 \%)$.Type $V$ was least common in female $5(0.3 \%)$. Whereas we have not found type $V$ lip prints in any of male participants.

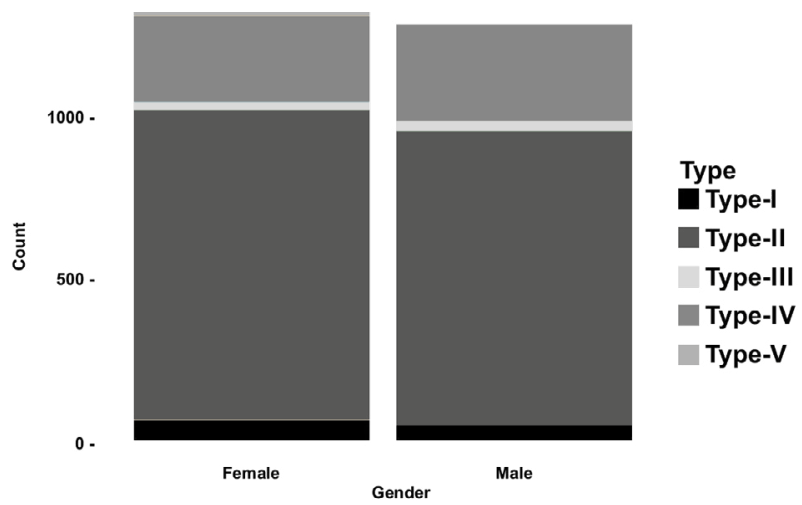

Figure-2. Percent distribution of types of lip prints in male and female.

Types of lip prints and frequency in study population.

The study samples included more males (106) as compared to females (110). Twenty six pair of male whereas twenty eight pair of female babies was included in the study. Male to female gender ratio was 1:1.02. In all the families father Maximum and Minimum Resemblance was $87.51 \%$ \& $25 \%$ while mother Maximum and Minimum Resemblance was $91.67 \%$ \& $33 \%$ respectively.

\section{Types of lip shapes in individuals of 54 families}

Lip shapes of all the individuals were characterized under 8 different types according to website http:// clevergirlhelps.tumblr.com/post/111062851767/ shapestypes-of-lips. Distributions of different types of lip shapes in all individuals of families are given in table no 7 . We observed that lip shape 7 was the most frequent lip shape type in most of individuals. Followed by type 1 , type 8 , type 5 , 
type 3 , and type 2 with the frequency of $42.3,34$, 13, 6.4, 2.7 And 0.9 respectively. Lip shape 4 and lip shape 6 were not present in any of the studied sample.

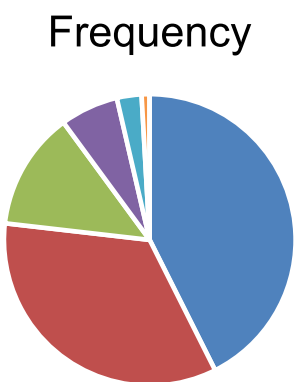

lip shape7 lip shape1 lip shape8 — lip shape5

lipshape3 lipshape2 lip shape4 lip shape6

Figure-3. Frequency of lip shape types in 216-individuals.

\section{Comparison of Lip Shapes with Lip Print Patterns}

Analysis was performed to investigate the relationship between lip shapes and types of lip prints identified in 4 quadrants. Lip shape type 7 was most commonly found in individuals containing lip print type II. Lip shape type I, 8, 5, and 3 were found to be associated with lip print type II. Lip shape type 7, 1, 8 and 5 were also associated with lip print type IV too. Percent frequencies of lip shapes compared with lip print types for all the under study individuals is given in Figure.

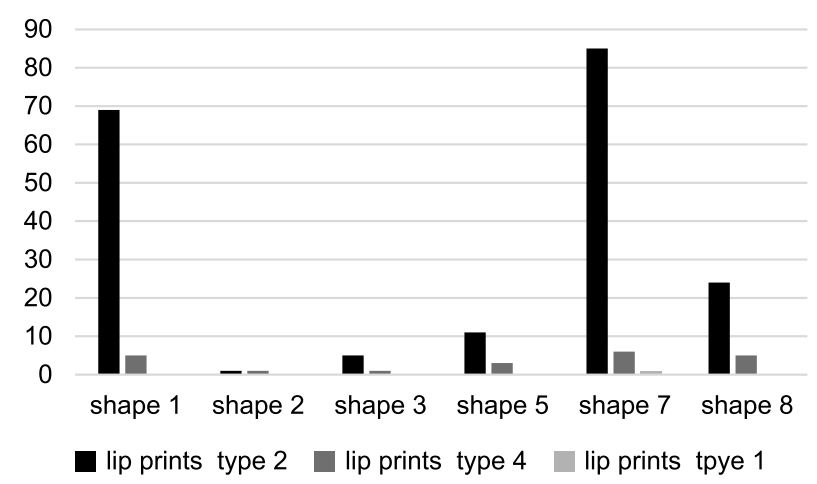

Figure-4. Frequencies of lip shapes compared with the types of lip print.

\section{DISCUSSION}

The present study is a valuable addition to the available data of cheiloscopy on biological families. The study is unique with the largest data set of 54 different families having biological babies as compared to the previous studies and is first of its kind in Pakistan and in the world.

Our Study on biological babies with parent's lip print analysis has shown that lip prints are not equally distributed in families but quite similar and some degree of similarity concerning the predominant grooves pattern is present in relatives. $^{8}$

We found no significant difference between biological babies and parents. statistically significant resemblance of lip print pattern were found between father to biological babies (Z$0.4978, P<0.05)$ and mother to biological babies $(Z-0.49917, P<0.05)$ to be. This proves statistically significant Pattern of inheritance from father to biological babies and mother to biological babies. A substantial variance in type of lip prints found in dissimilar families $(p=0.0001)$ by Two way ANOVA test. While parents and biological babies shown no significant difference in them. Overall the average inheritance from father is $62.618 \%$ and from mother is $70.49 \%$. Lip prints are not identical but similarities of lip prints between parents and children's were found accounting for the hereditary to play a major role. ${ }^{9,10}$ This indicates that lip print patterns of biological babies shows a marked similarity with parents and can be used for comparison of lip prints within the family. These results are consistent with previous studies indicating significant level of similarities and genetic factor in biological babies. ${ }^{11,12}$

We observe that individuals don't have particular pattern in them in a particular quadrant of lip but that appeared to have a mixture of different patterns. It was found that they shared some similarity in the grooves but the detail features of lip prints were not same. We found in our analysis no similarity was seen neither in between two biological babies nor between the biological babies with their parents. Our study shares several common features with other data published in literature. ${ }^{13,14,15}$ In the present study, lip prints of study participants did not match with each other. Thus, this finding validates that lip 
prints are distinctive similar to finger prints and thus have forensic significance. ${ }^{16}$

Furthermore In the studied individuals, no two lips showed single type of lip print in whole of lip. Mostly mix type of lip prints were seen in all of biological children and their parents. In all families biological children shared features of lip print resemblance with father and mother that was found to have statistically significant association $(p=<0.05)$. None of the biological child in any of the family showed complete lip print resemblance either with father or mother. All of biological baby's pairs were similar but not absolutely identical and their characteristic features resembled either father or mother, which is similar to the studies performed on twins children's. Biological babies constitute a peculiarity inherent to cheiloscopy. ${ }^{17,18,19}$

The data of the present study also proved very helpful to see if there is any correlation of the lip print types with gender. There are several studies available that showed the relationship of type II lip print either with male or female while other studies showed the lip print type IV as most common in both sexes. ${ }^{20,21}$ The results of the present study showed that lip print type II were the dominant type in both genders. However, from the analysis of all lip prints types in both male and female gender, we found that percentages of lip print types were consistent in both gender. None of the individual lip print type showed more specification to male or female gender. ${ }^{22}$ Similarly, in our study both genders exhibited lip print type II, IV, I, III and $\mathrm{V}$ while other studies concluded that lip print types I and II are specific to female gender and lip print type III, IV, V are male gender. ${ }^{23,24}$ However, interestingly type $\mathrm{V}$ is not only the least common type observed in accordance to other study but is found only in females (14.4\%)..$^{25,26}$

The available data was used to find out the lip shapes of the individuals and to see if there is any correlation between the lip shape and lip print type which could subsequently be used for forensic case work study. It was observed that lip shape 7 was most common in 92 individuals (42.39\%), and lip shape 1 (34.10\%) was second most common present in individuals followed by Lip shape $8(13.36 \%), 5(6.45 \%), 3(2.76 \%)$, 2(0.92\%). Lip shape $4(0 \%)$ and $6(0 \%)$ were least common types present in studied individuals. The data did not show any specific association of the lip print type with lip shape. The type II lip print apparently showed higher association with lip shape 7 and 1 but it is distributed in all the lip shapes. However, further studies on population based big data set need to be conducted to reach a definite conclusion that if there is any association of the lip shape with lip types.

\section{CONCLUSION}

Based on the analysis in the current study, lip prints of studied parents with two babies participants did not match with each other. They are not specific to any gender in biological groups. Also lip print types are not associated with any specific lip shape. It is considered feasible to apply lip prints features in personal identification.

\section{Copyright@ 25 Aug, 2021.}

\section{REFERENCES}

1. Ludwig $A$, Page $H$. An investigation into the dynamics of lip-prints as a means of identification. Australian Journal of Forensic Sciences 2012; 44(2): 169-181, DOI :10.1080/00450618.2011.630413.

2. N, Badive S. A study of distribution, sex differences and stability of lip print patterns in an Indian population. Saudi Journal of Biological Sciences 2017; 24, 1149-1154.

3. Kapoor N, Tiwari P. Study of lipprint among the population of Marathi community. International Journal of Scientific and Research Publications 2013; 3(2): 1-8.

4. Moshfeghi M, Beglou A, Mortazavi HN. Morphological patterns of lip prints in an Iranian population. J Clin Exp Dent. 2016; 8(5): e550-e555.

5. Loganadan S, Dardjan M, Murniati N, Oscandar F, Malinda $Y$, Zakiawati D. Preliminary research: Description of lip print patterns in children and their parents among deutero-malay population in Indonesia. Int J of Dentistry 2018; 2-7.

6. Jaishankar S, Jaishankar $\mathrm{N}$, Shanmugam S. Lip prints in personal identification. J Indian Acad Dent Specialists 2010; 1(4): 23-26. 
7. Randhawa K, Narang RS, Arora PC. Study of the effect of age changes on lip print pattern and its reliability in sex determination. J Forensic Odontostomatol 2011; 29(2): 45-51.

8. Fernandes LCC, Oliveira JDA, Santiago BM, Rabello PM, Carvalho MVDD, Campello RIC, Soriano EP. Cheiloscopic study among monozygotic twins, nontwin brothers and non-relative individuals. Braz. Dent. J 2017; 28(4).

9. Thakur B, Ghosh B, Puri N, Bansal R, Yadav S, Sharma RK. A comparative study of lip print patterns in monozygotic and dizygotic twins. Int J Res Med Sci 2017; 5(5): 2144-2149.

10. Borase AP, Shaikh S, Mohatta A. A study of lip prints among North Maharashtrian population. J Adv Oral Res 2016; 7(3):20-25.

11. Patel S, Paul I, Astekar MS, Ramesh G, Sowmya G. A study of lip prints in relation to gender, family and blood group. International journal of oral and maxillofacial pathology 2010; 1(1): 4-7.

12. Mohan M, Uma Maheswari TN. Prevalence of different subtypes of type II lip prints among students of saveetha dental college. Int J Forensic Odontol 2017; 2:9-12.

13. Sharma P, Saxena S, Rathod V. Cheiloscopy: The study of lip prints in sex identification. Journal of forensic Dental sciences 2009; 1: 24-27.

14. Aggrawal A. The importance of lip prints. Dr. Anil Aggrawal's Forensic Files 2010; 2(2). Online] available at:http://www.geradts.com/ anil/index.html.

15. El Domiaty MA, Al-Gaidi SA, Elayat AA, Safwat MD, Galal SA. Morphological patterns of lip prints in Saudi Arabia at almadinah almonawarah province. Forensic Sci Int 2010; 200: 179.e1-9.

16. Venkatesh R, David MP. Cheiloscopy: An aid for personal identification. J Forensic Dent Sci 2011; 3(2): 67-70.
17. Maheswari TU, Gnanasundaram N. Role of lip prints in personal identification and criminalization. Anil Aggrawal's Internet Journal of Forensic Medicine and Toxicology 2011; 12(1): 21.

18. Debta FM, Debta P, Bhuyan R, Swain SK, Sahu MC, Siddhartha S. Heritability and correlation of lip print, palm print, fingerprint pattern and blood group in twin population. J Oral Maxillofac Pathol 2018; 22(3): 451-466.

19. Ragab AR, El-Dakroory SA, and Rahman RH. Characteristic patterns of lip prints in Egyptian population sample at Dakahlia Governorate. Int J Legal Med 2013; 127: 521-7.

20. Rastogi P, Parida A. Lip prints-an aid in identification. Australian Journal of Forensic Sciences. 2012 Jun 1; 44(2):109-16.

21. Pawar, S.R., Anjeneya, S., Pandey, R., Patel, T. 2014. Cheiloscopic comparison of female sex workers with sexually inactive females as control, a prospective study. International Journal of Medicine and Allied Health Sciences, 2(1): 184-188.

22. Jaishankar S, Jaishankar N, Shanmugam S. Lip prints in personal identification. $J$ Indian Acad Dent Specialists 2010; 1(4): 23-26.

23. Dongarwar GR, Bhowate RR, Degwekar SS. Cheiloscopy-method of person identification and sex determination. Sci Rep. 2013; 2:1-4.

24. Mujoo, S., Sakarde, S., Sur, J., Singh, A., Khan, F., Jain, S., Deeplaxmi, R. Cheiloscopy and Palatoscopy: A novel tool for sex identification. Chettinad Health City Medical Journal, 2014; 146-150.

25. Kumar GS, Vezhavendhan N, Vendhan P. A study of lip prints among Pondicherry population. Journal of forensic dental sciences. 2012 Jul; 4(2):84.

26. Gupta S, Gupta K, Gupta O. A study of morphological patterns of lip prints in relation to gender of North Indian population. J Oral Biol Craniofac Res 2011; 1(1): 12-16.

\begin{tabular}{|c|l|l|l|}
\hline \multicolumn{2}{|c|}{ AUTHORSHIP AND CONTRIBUTION DECLARATION } \\
\hline No. & \multicolumn{1}{|c|}{ Author(s) Full Name } & \multicolumn{1}{|c|}{ Contribution to the paper } & Author(s) Signature \\
\hline 1 & Aftab Alam Tanoli & $\begin{array}{l}\text { Concept \& Design of study, Drafting, Data } \\
\text { analysis, Final approval of version. }\end{array}$ \\
\hline 2 & Omair Khan Jadoon & Concept \& Design of study, Data analysis. \\
\hline 3 & Nayella Nijat Bangash & $\begin{array}{l}\text { Drafting revisiting critically. } \\
\text { Revisiting critically, Final approval of } \\
\text { version. }\end{array}$ \\
\hline 4 & Qurrat Ul Ain & \\
\hline
\end{tabular}

